\title{
Lo menos malo no deja de ser malo: la consolidación del personal estatutario en Atención Primaria
}

\begin{abstract}
$N_{\mathrm{o}}$ o es este el editorial que tenía a punta de pluma, pero el desarrollo de los acontecimientos ha hecho que me encontrara con este encargo, al que no podía negarme. Sé que en este caso, en la defensa de una u otra posición, hay sin duda opiniones bien intencionadas pero artefactadas, -las mías supongo que también - por las distintas y variadas experiencias individuales. Pero aún aceptando esa posibilidad creo interesante contribuir al debate. De algún modo mi pasado, mi presente y mi propia situación laboral y personal me obligaban a no eludirlo y por tanto a compartir mis pensamientos, a veces contrapuestos, y tal vez contribuir con ellos al enriquecimiento de ese meta-pensamiento que pienso aún comparten los médicos de familia de España.

Este problema, importante pero circunstancial, nos aleja de un análisis y un posicionamiento serio en relación a la política de personal del sistema sanitario público español que, si bien debería ser una de sus grandes prioridades, lejos de serlo, acaba siendo uno de nuestros grandes problemas como colectivo profesional mayoritariamente vinculado al mismo. La insatisfacción laboral, la falta de estímulo profesional, la falta de incentivos reales al buen hacer, la falta de proyección y perspectiva, tanto en la carrera profesional individual como en el rumbo del servicio, no se van a ver resueltas sino afianzadas en un diseño de vínculo laboral que a mi juicio se ha quedado obsoleto e incapaz de incorporar las mejoras o los cambios que la organización del sistema y la población necesitan.
\end{abstract}

En realidad existe un gran miedo y, derivado de él, resistencia a los cambios. No es posible que después de todos estos años de quejarnos de que en esta empresa todo vale, de que no se valora a quien lo hace bien ni se disuade al que lo hace mal, vayamos a defender un modelo de selección y vínculo profesional de tipo pseudo-funcionarial.

Se entiende con facilidad que a aquéllos que estén sometidos a la angustia de conservar o perder el empleo o a la responsabilidad de ampararles o defenderles les va a resultar muy difícil abstraerse a esa necesidad básica y ponerse a proyectar futuro. Nuevamente lo urgente afecta a lo importante.

Todo intento honesto de recobrar la normalidad o el bienestar profesional merece ser considerado. La tantas veces aireada normalización profesional de los médicos de Atención Primaria no sólo parece no terminarse sino que lleva camino de ampliarse y complicarse en su heterogeneidad y en sus actores. Ya no sólo hay "familias" y "generales", sino 
que dentro del propio colectivo de "familias" la heterogeneidad crece. En este sentido el tiempo podría estar jugando en contra de esa posición de cierto equilibrio que, a lo largo de estos años, se ha ido forjando en el entorno semFYC y tal vez por ello podría ser hoy necesario invertir esfuerzos en la construcción de un escenario en el que pueda anidar a gusto el cada vez más amplio y heterogéneo colectivo de los médicos de familia de España.

\section{LOS ELEMENTOS BIOGRÁFICOS Y GENERACIONALES}

Cuando se habla de este problema en el fondo se está hablando también de personas individuales, de profesionales, de proyectos y ciclos vitales, de procesos de maduración profesional que no tienen vuelta atrás.

Desde la aprobación de la Ley General de Sanidad en 1986, en la mayor parte de las Comunidades Autónomas sólo ha habido uno o dos concursos oposición y varias Ofertas Públicas de Empleo (OPE) anuladas. En algunas, cerca del $80 \%$ de los médicos son interinos, como interinos son o han sido gerentes, directores médicos, directores de centros de salud, coordinadores de unidades docentes y por supuesto la mayor parte de los tutores. Mucho de lo bueno y malo que se haya hecho en estos años, lo han hecho interinos. Cuando muchos médicos de familia, hoy tutores e interinos, comenzaron a trabajar, sus actuales residentes aún no habían iniciado el bachiller.

El paso del tiempo ha introducido en este problema un componente biográfico y generacional que resulta ineludible. El elemento tiempo ha hecho que potencialmente confluyan en competencia varias generaciones de profesionales hecho que, en esta magnitud, nunca hubiera ocurrido en una situación de normalidad administrativa, lo que hace que esos valores individuales que en los procesos de selección se consideran en la fase de concurso, ejerzan aquí una gran presión por tener un importante protagonismo en el conjunto del proceso.

¿Es esto inadecuado? No lo sé.

\section{LA URGENCIA IMPERIOSA}

Ni siquiera el intenso conflicto protagonizado por el poderoso colectivo de interinos de hospitales ha logrado forzar la voluntad ni por supuesto la creatividad del Ministerio en relación a este asunto.

Lo normal sería pensar que el Ministerio de Sanidad o el INSALUD estuvieran preocupados por los efectos que un concurso-oposición pudiera tener en la ruptura de los equipos clínicos en muchos de los hospitales de INSALUD o incluso en la continuidad asistencial y relación 
médico-paciente en muchos equipos de Atención Primaria, pero a mi juicio está siendo otra la razón que ha actuado como detonante de esta prisa por resolver un problema viejo y es la bien atinada certeza que existe en el Ministerio de la tensa situación por la que pasa hoy el conjunto del sistema sanitario, con enormes problemas no sólo en la gestión de sus recursos humanos, sino también en su retribución, el deterioro y envejecimiento de la estructura de los centros asistenciales, los retrasos en la actualización tecnológica, la pérdida de norte en las políticas sanitarias y de salud, la desinversión en Atención Primaria, la masificación de las consultas, las listas de espera, etc., etc., lo que hace altamente probable el estallido de un conflicto generalizado y de profundo calado.

Comienzan pues a encenderse muchas luces rojas en el panel de mandos: conflicto de interinos, plataforma 10 minutos, conflictos de Atención Primaria y de hospitales en Canarias, fachadas de hospitales que se desploman, listas de espera, informe del defensor del pueblo sobre el aumento de las quejas de los usuarios de la sanidad, graves problemas en salud pública, creciente incremento del gasto vinculado a la prescripción, etc.; y la desaparición de INSALUD, con la transferencia de competencias a las Comunidades Autónomas, permitiría a la Ministra de Sanidad, sin necesidad de hacer política sanitaria, quitar presión a su caldera, repartiéndola entre el resto de comunidades que están por transferir; pero esas comunidades parecen no estar dispuestas a admitirlas hasta ver resuelta la parte más visible del conflicto, que es hoy la de un colectivo de médicos interinos de hospitales en pie de guerra.

\section{EXCEPCIONALIDAD SIN PROPÓSITO DE ENMIENDA}

La situación de excepcionalidad planteada es hoy, en sanidad, parecida a la que se vivió hace unos años en educación y anteriormente en otros colectivos funcionariales o estatutarios pero, al contrario de lo ocurrido con aquéllos, aquí se está hablando de ello con una importante falta de autocrítica y sobre todo de propósito de enmienda. Se elude entrar ahí y tampoco hay garantías o simplemente indicios de que en el futuro las cosas vayan a ser mejores. El proyecto de consolidación se ocupa de dar una salida circunstancial a este problema, pero no sienta ninguna base para que no vuelva a ocurrir nunca más lo que todavía hoy está ocurriendo, es decir las bases de buenos sistemas de selección que impidan que oposición tras oposición, oferta pública tras oferta pública, se paralicen por los juzgados o incluso se anulen.

Hay en esta medida un problema fundamental: se acude a apagar un fuego, y esto es lo único que preocupa. Nuevamente se lanzan a correr ante nosotros los señuelos de la carrera profesional, los sistemas de mantenimiento de la competencia, tantas veces aparcados. No me lo tomo en serio, no me lo creo, más ahora cuando el consenso necesario no 
va a ser entre cinco, sino entre las 17 Comunidades Autónomas, salvo que se pretenda crear 17 sistemas genuinos de carrera profesional y mantenimiento de la competencia.

\section{CUESTIONANDO ALGUNOS TÓPICOS: IGUALDAD}

Podríamos intentar emular a los juristas y ponernos a analizar los aspectos jurídicos, tanto desde la perspectiva de la filosofía del derecho y principios constitucionales como desde la jurisprudencia, que pudieran servirnos para apuntalar uno u otro argumento en relación al problema y su solución. De hecho el lector interesado puede solicitarle a semFYC la multitud de informes jurídicos y dictámenes que obran en su poder o incluso a cualquiera de los sindicatos del sector. Siempre se encuentran cuerdas jurídicas para amarrar una -cualquiera- línea argumental.

Sin embargo, muchos de los dictámenes solicitados en relación a este proyecto ponen en duda que el ejercicio en diferentes comunidades autónomas, o incluso países - si pensamos que estamos en un ámbito europeoconfiera diferente valor a las capacidades de un profesional, que es reflejado de forma distinta en la valoración de la experiencia profesional. ¿Qué más puedo decir? No encuentro ningún argumento que me permita defender que un año de ejercicio profesional en Carbayín me imprima un valor diferencial sobre ese mismo periodo de ejercicio en Valleseco, por más que ambos sitios sean sustancialmente distintos e igualmente entrañables para mí.

Pero un argumento al contrario también sería posible y alguien podría plantear que la experiencia adquirida en Carbayín, para los habitantes de Carbayín sí es un valor, del mismo modo que lo es para los de Valleseco, que el médico que les conoce y que lleva años al cuidado de su salud pueda seguir haciéndolo. ¿Se piensa realmente en ellos cuando se diseñan los procesos de selección?

\section{CUESTIONANDO ALGUNOS TÓPICOS: MÉRITO Y CAPACIDAD}

Cuando surgen este tipo de debates, y no es la primera vez, siempre hay un sector que rechaza la oposición, tratando de evadir la arena, el cara a cara y pide la consolidación o el reconocimiento de unos "derechos adquiridos" y otro que se atrinchera en la defensa del concurso oposición como la fórmula menos mala. ¿Es uno u otro menos interesado en su planteamiento? Pienso que no.

En ese vaivén de argumentos y réplicas existe la tendencia a asimilar capacidad a oposición (examen) y mérito a concurso, así como también el automatismo a afirmar o defender que quien no supera la primera es un incapaz y no tiene derecho a acudir al concurso, a hacer valer sus 
méritos. Sin embargo, tanto el examen como el concurso parecen tener el mismo propósito, es decir, evaluar... la competencia, la aptitud y la idoneidad de los aspirantes (sic) y su orden y modo de aplicación son potestad de los tribunales. Una lectura atenta de la Ley 30/1999 de selección y provisión de plazas de personal estatutario de los servicios de salud (BOE del 6/10/99), describe perfectamente las fases de oposición y concurso y cómo cualquiera de las dos puede ser previa a la otra.

Si algo caracteriza al licenciado en medicina de nuestro país es su enorme capacidad para responder preguntas tipo test y su dramática incapacidad para ver pacientes. Es totalmente discutible que el principio de capacidad se garantice mediante una prueba de conocimientos, por más que pretenda ser un mecanismo indirecto de medición de la misma. En mi opinión, estas pruebas están fundamentalmente diseñadas para establecer unos mecanismos inapelables de selección y no para buscar a los profesionales más capaces. Hemos, por tanto, de rechazar su valor dado que miden cosas distintas -y no sé cuáles- a lo que se pretende buscar: los profesionales más competentes. Si vamos más allá, a los sistemas más sofisticados de evaluación, como el ECOE y similares, vemos que permiten mejorar algunos aspectos cualitativos de lo evaluado y se acercan un poco más a la realidad de la práctica clínica, del desempeño, pero están aún muy alejados de poder medir lo que sería realmente un médico de familia competente. Puestos a examinar, ¿por qué no un test psicotécnico o una evaluación de actitudes?

Por otro lado, muchos de los denostados méritos -valor de una cosa debido al trabajo o habilidad puesto en ella- que se valoran en las fases de concurso seguramente podrían ser un reflejo, indirecto también, pero más poderoso de capacidad que la prueba de conocimientos. ¿Cómo es posible que la formación especializada, en servicio, viendo pacientes, haciendo multitud de guardias y cumpliendo con un currículo establecido y supervisado, ni siquiera llegue a valer lo mismo que vale ese tiempo de trabajo sin supervisión ni formación estructurada en un no especialista? Es absurdo. Es humillante.

En mi opinión el sistema está viciado de base. No sólo hemos de cuestionar la validez de los exámenes como sistema de medición de la capacidad de cualificados profesionales sino que hemos de denunciar la arbitrariedad en el establecimiento de criterios para la valoración de los méritos.

No imagino otra medida -directa o indirecta- de capacidad -profe sional-fiable -si es que realmente nos preocupa garantizar el mandato constitucional- que aquélla que sea capaz de medir la efectividad de nuestra práctica, es decir, la capacidad real para resolver los problemas relacionados con la salud de los pacientes y sus familias y, si queremos, también la eficiencia en el desempeño de dicha función.

El editorialista se ha vuelto loco, pensará más de un lector. Es fácil tirarlo todo por la borda, pero ¿dónde están las alternativas? ¿Quiere esto 
decir que no hay buenos sistemas de selección? No, seguramente que sí los hay. Lo que tal vez no haya, o no sea viable su aplicación, son buenos sistemas masivos de selección, capaces de garantizar realmente los principios de igualdad, capacidad y mérito. Pero, ¿y es que debería haberlos? ¿no podría haber otros buenos modos de concebir el sistema que hiciera impensables estos estériles conflictos?

\section{LA SOLUCIÓN MENOS MALA}

Después de tanto nadar nos ahogamos en la orilla y nos vemos cantando, recién estrenado siglo, las loas de las oposiciones del Estado como la forma más adecuada de seleccionar a los más capaces. Llevamos años jugando a implantar nuevos sistemas de gestión y ahora nos vienen con éstas. En una sociedad moderna y democrática en la que el ciudadano tiene derecho a recibir unos servicios de alta calidad no se entienden las rancias estructuras funcionariales basadas en la "propiedad" de los puestos de trabajo. Hemos de ir hacia estructuras más funcionales, no sólo respetuosas sino "mimadoras del buen trabajador", pero en ningún caso cautivas de él.

Pensemos en ¿qué es ser un buen médico de familia? y reflexionemos si realmente las oposiciones conocidas tratan de medir eso. A mi juicio no. Ni los concursos oposición lo valoran ni la empresa -llamémosla asílo incentiva. Por liarla aún más, me atrevería a decir que los buenos profesionales, que creo sinceramente que somos la mayoría, no tenemos futuro en esta empresa, tal y como está concebida, si es que aspiramos a algo más que a ser unos dóciles y resignados bienmandados. Ésta es la triste realidad actual.

Aceptemos pues que los sistemas de selección para el acceso a puestos de médico del sistema público son enormemente imperfectos si lo que pretenden es valorar a los mejores, y hasta ahora también lo han sido simplemente para seleccionar personas, dado que la mayoría de ellos están impugnados o anulados.

El reconocimiento explícito de esa situación será el primer hecho que nos permita pensar que las cosas algún día podrán mejorar. Para los médicos de familia, que nos esforzamos cada día por hacer las cosas un poco mejor, un sistema menos malo es simple y llanamente malo.

J. R. VÁzouez Díaz

Coordinador de la U.D. Medicina de Familia y Comunitaria. "La Laguna - Tenerife Norte" 